DOI: https://doi.org/10.35699/2238-037X.2019.14730

\title{
RECONHECimEnTO E TRABALho ${ }^{1}$
}

\author{
Recognition and work \\ Reconnaissance et travail
}

Emmanuel Renault²

\section{Resumo}

Este artigo se propõe comparar a maneira na qual a questão do reconhecimento do trabalho é posta no modelo de Honneth e na psicodinâmica do trabalho. Mesmo se a questão do trabalho tenha sido central em Honneth, ela não ocupou sempre o primeiro lugar de sua reflexão, e esta foi visada segundo diferentes pontos de vista ao curso de sua evolução intelectual. Este é o encaminhamento que se propõe, num primeiro momento, retraçar a fim de fixar os termos de comparação. Mas o modelo de Honneth igualmente foi utilizado de diferentes maneiras por sociólogos do trabalho e, sobre este ponto também, a confrontação com psicodinâmica do trabalho mereceria ser desenvolvida, sugerir-se-á como emprega-la num segundo momento.

Palavras-chave: Habermas. Honneth. Ideologia. Neoliberalismo. Neomanagement. Reconhecimento. Divisão do trabalho.

\section{RÉSUMÉ}

Cet article se propose de comparer la manière dont la question de la reconnaissance du travail est posée dans le modèle de Honneth et dans la psychodynamique de travail. Même si la question du travail a toujours été centrale chez Honneth, elle n'a pas toujours occupé le premier plan de sa réfl exion, et elle a été envisagée selon différents points de vue au cours de son évolution intellectuelle. C'est ce cheminement qu'on se propose, dans un premier temps, de retracer afin de fi xer les termes de la comparaison. Mais le modèle d'Honneth a également été utilisé de différentes manière par des sociologues du travail et, sur ce point aussi, la confrontation avec la psychodynamique du travail mériterait d'être développée, comme on s'emploie à le suggérer dans un second temps.

Mots clés: Habermas. Honneth. Idéologie. Néolibéralisme. Néomanagement. Reconnaissance. Division du travail.

\section{ABSTRACT}

This article intends to compare the question of acknowledgment of work between Honneth's model and psychodynamics of work. However the question of work has always been a central one for Honneth, it didn't always take place at the first plan of his reflection, but it has been considered through many points of view during his intellectual evolution. First, we propose to retrace this progress in order to fix the terms of comparison. Honneth's model has also been used through different ways by sociologists of work. At this point, confrontation with psychodynamics of work should be more developed as we suggest in the second part of the article.

Keywords: Habermas. Honneth. Ideology. Neoliberalism. Neomanagement. Acknowledgment. Division of Work.

\footnotetext{
${ }^{1}$ Artigo originalmente publicado em Travailler, 2007/2, n. 18, p. 119-135. Tradução: Antônio José Lopes Alves. Revisão técnica: Daisy Moreira Cunha. Ademais, informa-se ao leitor que o artigo não possui, pelas características do periódico francês em que apareceu originalmente, uma seção destinada a referências. Com o fito de preservar o formato autorizado pelo autor, resolveu-se publicar a tradução sem este adendo.

${ }^{2}$ Professor do Departamento de Filosofia da Universidade de Paris-Nanterre (França), atua como pesquisador junto ao SOPHIAPOL Laboratoire de Sociologie, Philosophie et Antropologie Politique, ligado à mesma universidade. E-mail: emmanuel.renault@parisnanterre.fr.
}

Trabalho \& Educação | v.28 | n.2 | p.51-62 | maio-ago | 2019 
A questão do trabalho permite apresentar certas motivações centrais da Teoria do Reconhecimento desenvolvido por Axel Honneth assim como a maneira pela qual alguns sociólogos alemães se apropriaram desta teoria. A teoria do reconhecimento foi elaborada no quadro de uma crítica à distinção habermasiana do sistema e do mundo da vida, distinção a qual tendia a fazer da economia uma esfera que, contrariamente a esta, somente poderia ser criticada do ponto de vista da racionalidade instrumental, os problemas postos pelo trabalho sendo assim reduzidos a problemas técnicos. É a esta redução que Honneth tenta replicar sublinhando que a esfera da economia e do trabalho é igualmente atravessada por exigências normativas específicas. De outra parte, a questão do trabalho permite apresentar algumas ilustrações sociológicas as mais interessantes da teoria do reconhecimento. Honneth dirige hoje o Instituto de Pesquisa Social de Frankfurt que reagrupa psicólogos, sociólogos do direito, sociólogos das desigualdades e sociólogos do trabalho. É no seio deste último grupo que a relação das pesquisas empíricas com as hipóteses da teoria do reconhecimento ganha maior amplitude. Esta relação não toma, entretanto, a forma de uma simples aplicação, porquanto as referências a Honneth são indissociáveis de uma transformação, quiçá de uma crítica, de algumas de suas teses.

Começaremos por descrever a função que desempenha o conceito de trabalho em Honneth, antes de apresentar algumas das questões retomadas pela sociologia do trabalho inspirada pela teoria do reconhecimento. O objetivo não é simplesmente expor o conteúdo de análises pouco conhecidas na França, mas também confrontar esses approaches com aqueles da Psicodinâmica do Trabalho com fito de fazer aparecer os pontos de convergência e as especificidades de umas e outras.

\section{O trabalho em Honneth}

A questão do trabalho ocupa um lugar ambíguo na teoria do reconhecimento desenvolvida por Honneth. De uma parte, com efeito, um dos motivos fundamentais desta teoria se relaciona com a necessidade de elaborar uma "concepção crítica" do trabalho. Mas, de uma parte, o conceito de trabalho não ocupa posição decisiva no dispositivo teórico definitivo.

\section{ConCEPÇÃo CRÍtICA do TRABALHO E CRÍTICA DA DISTINÇÃo SISTEMA/MUNDO VIVIDO}

Para apresentar o papel que a questão do trabalho desempenha na gênese da teoria do reconhecimento, dois textos merecem uma atenção particular. O primeiro data de 1980: um artigo retomado em tradução inglesa no volume The Fragmented World of the Social (State University Press, Albany, 1995), intitulado "Work and Instrumental Action. Onthe Normative Basis of Critical Theory ", mas ausente dos volumes de artigos publicados em alemão por Honneth (cf.supra no presente dossiê). Neste artigo, ele parte da maneira pela qual Marx tentou fundar sua teoria e sua crítica da sociedade capitalista sobre uma análise do trabalho, depois expõe certo número de aporias características deste empreendimento teórico-político, antes de explicar como autores contemporâneos, dentre os quais Habermas, tentaram resolvê-las. É definitivamente a Marx e a Habermas que são consagradas as análises as mais substanciais, e é nesta ocasião que Honneth desenvolve pela primeira vez a crítica da distinção habermasiana entre o sistema e o 
mundo vivido. Ele lembra que se encontra em Habermas uma crítica da tentativa marxiana visando fundar a emancipação no trabalho, a função emancipadora do trabalho sendo duplamente recusada: de uma parte, porque o potencial emancipador está situado num agir comunicativo o qual é estritamente oposto ao agir instrumental; de outra parte porque o trabalho é remetido à esfera social do "sistema", a qual é regida por normas funcionais do agir instrumental (esferas do dinheiro e da administração), a esfera do sistema sendo oposta àquela do mundo vivido, ela mesma regida por normas morais do agir comunicativo. Honneth considera que um tal dispositivo teórico é incapaz de considerar reivindicações que emergem do trabalho, e sublinha neste contexto a necessidade da elaboração de uma "concepção crítica do trabalho". Ele ilustra este ponto citando longos extratos de um artigo de Philippe Bernoux, intitulado "La résistance ouvrière à La rationalisation" (Sociologie du Travail,4:78), e lamenta que a sociologia francesa do trabalho, tal qual se desenvolveu a partir de George Friedmann, não tenha encontrado eco algum na Alemanha. Eis um primeiro ponto justificando uma comparação com a maneira pela qual a Psicodinâmica do Trabalho põe o problema do reconhecimento. A função que ela atribui ao reconhecimento está ligada efetivamente às modalidades da coordenação de atividades irredutíveis ao trabalho prescrito e, por isso mesmo, à distinção entre trabalho prescrito e trabalho real, a qual pode ser considerada como uma das teses características da tradição francesa tanto em ergonomia como em sociologia do trabalho.

A crítica da distinção entre sistema e mundo vivido será desenvolvida de modo mais aprofundado na obra de 1985 intitulada Kritik der Macht (A Critique of Power, em tradução inglesa). O acento da crítica se desloca aí ligeiramente, na medida em que não se trata mais simplesmente de contestar a capacidade crítica da distinção sistemamundo vivido, mas também da imagem da evolução social que ele associa à Habermas, a saber a imagem de uma evolução histórica animada por dois processos impessoais de racionalização análogos a processos coletivos de aprendizagem: um processo de racionalização moral no mundo vivido, e um processo de racionalização instrumental no sistema. Honneth se opõe a este modelo sublinhando a importância dos conflitos sociais para a evolução social, e assinala que os movimentos sociais não são somente impulsionados por motivações utilitárias, mas igualmente por motivações normativas. É precisamente esta dimensão normativa, ética e moral, imanente aos conflitos sociais, que a teoria do reconhecimento terá por meta explicitar, como o atesta o título completo da obra maior de Honneth: A Luta pelo Reconhecimento. Gramática moral dos conflitos sociais (1992, CERF, 2000, sem este subtítulo). Encontra-se aqui um segundo ponto de convergência com a Psicodinâmica do Trabalho. Contrariamente ao ponto de vista corrente em sociologia econômica, onde a atividade é explicada pelos quadros institucionais que a emolduram, a análise parte antes de tudo das expectativas normativas e da atividade deontológica/deôntica dos indivíduos no trabalho, e a evolução das instituições econômicas está relacionada aos conflitos sociais tendo o reconhecimento do trabalho por objeto de disputa.

$\mathrm{Na}$ obra de 1985, Honneth se empenha claramente em explicar que as instituições sociais devem ser consideradas como produções sociais suscetíveis de ser transformadas pelos conflitos sociais, e assinala que isto vale também tanto para as instituições do mundo da vida quanto para as instituições do sistema. Ele examina assim a imagem global de uma sociedade atravessada por conflitos de legitimidade entre grupos, e faz repousar assim a efetividade social das instituições sobre acordos normativos revisáveis. Ele conservará esta visão do social, e nos textos recentes (como 
no debate com Fraser, Redistribution or recognition, Verso, 2004), e precisará como esta pode aplicar-se às instituições econômicas: o funcionamento econômico aparece então, em consonância aos temas próximos do institucionalismo econômico onde a teoria das convenções, como solidária de acordos normativos entre grupos em torno de princípios institucionalizados permite satisfazer reinvindicações fundamentais de reconhecimento. Honneth prossegue assim sua polêmica contra a ideia de que as instituições econômicas podem ser avaliadas tão somente do ponto de vista de sua eficácia, assinalando de uma parte que elas repousam sobre compromissos normativos e, de outra parte, são o lugar de interesses normativos fundamentais para os indivíduos. Enquanto a filosofia política contemporânea tende a desertar a questão do trabalho acompanhando o duplo movimento de rendição da "esquerda social" e de uma invisibilização do trabalho levada ao paroxismo pela questão do emprego, Honneth sublinha que decisivas disputas normativas se travam no trabalho. Mesmo longe de admitir uma centralidade do trabalho, faz do trabalho uma forma fundamental da existência social que é caracterizada por um conjunto de exigências normativas específicas. Ele propõe assim uma imagem do trabalho que está nos antípodas dos discursos sobre o fim do trabalho e teorias da justiça e da dominação que fazem abstração das questões específicas ligadas à organização do trabalho. Neste sentido, ele adota um posicionamento teórico-político do qual as intenções podem sem dúvida ser comparados àqueles que animam os trabalhos de Dejours e sua equipe.

\section{O LUGAR AMBíguo do tRABALHO NA TEORIA do RECONHECIMENTO}

A Teoria do Reconhecimento colocou, portanto, certas de suas motivações na exigência de uma "concepção crítica do trabalho" e tem por objetivo explícito tematizar disputas normativas imanentes às instituições econômicas. De todo modo, a Teoria do Reconhecimento não descreve estas disputas normativas verdadeiramente sob a forma de uma teoria do trabalho, e esta é somente é assumida muito indiretamente como motivação inicial, aquela de uma "concepção crítica do trabalho". Esta não parece verdadeiramente desempenhar função determinante no dispositivo teórico definitivo.

A Teoria do Reconhecimento repousa sobre dois princípios fundamentais. O primeiro é que o nexo positivo a si de um indivíduo sendo intersubjetivamente constituído, é igualmente intersubjetivamente vulnerável, de sorte que a identidade pessoal está intimamente ligada à necessidade de reconhecimento, no sentido de uma necessidade de ver reconhecido nosso valor próprio por outrem. O segundo princípio é que existem três formas diferentes de reconhecimento, que correspondem a diferentes formas de relação positiva a si e a diferentes tipos de relação a outrem.

$\begin{array}{llll}\begin{array}{l}\text { Formas de } \\ \text { reconhecimento }\end{array} & \text { Relações primárias } & \begin{array}{l}\text { Relações jurídicas } \\ \text { (direito) }\end{array} & \begin{array}{l}\text { Comunidade de } \\ \text { valores }\end{array} \\ \begin{array}{l}\text { Relação } \\ \text { (positiva) }\end{array} & \text { Confiança em si } & \text { Respeito de si } & \text { Estima de si } \\ \begin{array}{l}\text { Dimensão } \\ \text { pessoal }\end{array} & \begin{array}{l}\text { Afetos e } \\ \text { necessidades }\end{array} & \begin{array}{l}\text { Responsabilidade } \\ \text { moral }\end{array} & \begin{array}{l}\text { Capacidade e } \\ \text { qualidades }\end{array}\end{array}$

A primeira forma de reconhecimento está ligada à constituição e à confirmação do valor de nossa existência como ser de afetos e necessidades; é o amor em sentido amplo que permite obter este reconhecimento, forma de reconhecimento que pode ser associada 
às exigências normativas do care (este misto de disponibilidade, de recursos e de cuidado, que foi teorizada por certas teorias feministas da justiça ${ }^{3}$ ).

A segunda forma de reconhecimento está ligada à constituição e à confirmação do valor de nossa liberdade, ela toma a forma do reconhecimento moral e jurídico e emerge do domínio tradicional da justiça.

A terceira forma de reconhecimento está ligada ao reconhecimento do valor social de nossas faculdades ou, mais precisamente, de nossa capacidade de ser útil à sociedade em seu conjunto ou a grupos sociais particulares. Porquanto esta demanda de reconhecimento se enderece não mais a um indivíduo particular, como no care, nem a um conjunto de indivíduos unidos numa sociedade, como nas reivindicações de justiça, mas à sociedade ou grupo social considerado como o todo ao qual pretendemos ser úteis, é indissociável de uma reivindicação de solidariedade 4 .

Esta terceira esfera a qual concerne especificamente à economia e ao trabalho, mesmo admitindo-se que as instituições de intimidade (ou das relações primárias) têm igualmente o reconhecimento do trabalho por meta, e mesmo se as normas do care do respeito da liberdade concirnam igualmente às instituições do trabalho ${ }^{5}$.

Em A Luta pelo Reconhecimento, a questão do valor das capacidades e qualidades não está conectada à questão específica do trabalho, mas àquela da luta entre os grupos para fazer reconhecer o valor de suas competências e especificidades. Referindo-se a Bourdieu, Honneth escreve "as relações de estima social são, nas sociedades modernas, o interesse de uma luta permanente, na qual os diferentes grupos se esforçam sobre o plano simbólico para valorizar as capacidades ligadas a seu mundo de vida particular e demonstrar sua importância para a vida comum" (tradução, p.154). Aqui é, sobretudo, o conceito de estima social que Honneth tenta explicitar, e se pode admitir que à primeira vista ao menos, a questão da estima social ultrapasse aquela do trabalho.

Mas parece que a partir do fim dos anos 1990, na sequência de sua posse na função como diretor do Instituto de Pesquisa Social, em colaboração com as pesquisas dos psicólogos e sociólogos do Instituto, da participação na elaboração de programas de pesquisas transversais (como aquele sobre os "paradoxos da modemização capitalista"), Honneth buscou aprofundar a teoria da terceira esfera sob forma de teoria do trabalho. Nos textos recentes, ele assinala assim que é antes por intermédio do trabalho que chegamos a valorizar nossas capacidades e a lhes dar uma utilidade social. É neste sentido que ele sustenta por vezes que a terceira forma de reconhecimento depende da inserção do indivíduo numa divisão social do trabalho onde o valor das capacidades de cada um encontra seu reconhecimento no seio da comunidade de valor de seus pares (veja-se notadamente o debate com Fraser).

O ponto de vista da teoria do trabalho permanece em Honneth aquele da filosofia social, e ele é, por conseguinte, difícil de confrontar com as análises por vezes sociológicas e psicológicas propostas pela psicodinâmica do trabalho. Arriscando-se, não obstante, a esta confrontação, dir-se-á sem dúvida que, do ponto de vista da Psicodinâmica do Trabalho, o approach de Honneth conduz a silenciar elementos essenciais da questão. O que é marcante no dispositivo teórico é inicialmente que o trabalho não é

\footnotetext{
${ }^{3}$ Sobre este ponto, ver Razões Práticas, 16: "Le souci des autres. Éthique et politique du care" (sob a direção de P. Paperman e S. Laugier), 2005.

${ }^{4}$ Para esta articulação do care, da justiça e da solidariedade, ver Honneth, "Dezen- trierte Autonomie. Moralphilosophische Konsequenzen aus der Subjektkritik", in Das Andere der Gerechtigkeit, Suhrkamp, 2000.

${ }^{5}$ Sobre este ponto, ver E. Renault, L'Expérience de l'injustice. Reconnaissance et clinique de linjustice, La Découverte, 2004, p. 193 sq. 
verdadeiramente analisado como uma atividade, mas, sobretudo, como um processo de valorização das capacidades, cujas condições sociais são deixadas nas sombras: em quais condições uma atividade pode ela mesma oferecer ao indivíduo uma ocasião de dar um valor social a suas capacidades? Em que esta valorização depende das condições de emprego e em que estas dependem das condições de trabalho? Quais são os tipos de reconhecimento decisivo ao seio das relações de trabalho? Estas questões permanecem sem resposta. Disso resulta notadamente que a questão do reconhecimento da realidade e do valor do trabalho não é verdadeiramente posta. Honneth parece distinguir, de uma parte, um esforço visando a que as capacidades de um grupo sejam reconhecidas pelo conjunto da sociedade (solidariedade) e, de outra parte, o reconhecimento das capacidades de um indivíduo graças a sua inserção numa comunidade de valores; ele parece, afora isso, considerar que a ideia de divisão social do trabalho permite conectar os dois. O que permanece então inexplorado é o conjunto dos problemas ligados ao que se poderia chamar de divisão técnica do trabalho, isto é a questão do reconhecimento ao seio da atividade coordenada e cooperativa do próprio trabalho, questão a propósito da qual Christophe Dejours mobiliza precisamente o conceito de reconhecimento, lançando mão notadamente da distinção entre julgamento de perfeição (reconhecimento da realidade do trabalho pelos colegas) e julgamento de utilidade (reconhecimento do valor do trabalho pela hierarquia).

Outro debate possível com a Psicodinâmica do Trabalho concerne à extensão dada ao conceito de reconhecimento. Considerada do ponto de vista de Honneth, a Psicodinâmica do Trabalho estuda somente uma das três formas de reconhecimento. Ela propõe uma teoria parcial, e não global, do reconhecimento. Considerada do ponto de vista da Psicodinâmica do Trabalho, em Honneth falta a centralidade do trabalho e se estabelece uma homogeneidade ilusória entre as três formas de reconhecimento: ele desenvolve o tema da centralidade do reconhecimento lá onde haveria de desenvolver aquele da centralidade do trabalho. É verdade que existam expectativas de reconhecimento em esferas outras que aquela do trabalho e, neste sentido, a distinção entre três formas de reconhecimento pareceria justificar-se. Entretanto, os desejos de reconhecimento ligados à esfera da intimidade não podem sempre ser distinguidos daqueles de reconhecimento próprios ao trabalho. Disso testemunha o fato de que as exigências normativas do care tomam sempre corpo num trabalho de caring ${ }^{6}$.

Quanto às expectativas de reconhecimento claramente independentes do trabalho, elas fornecem um ponto de vista crítico muito frágil, em razão da variedade e da força dos investimentos narcísicos dos quais elas são objeto. E contanto que elas não se concentrem especificamente sobre o fazer, mas no ser dos indivíduos, arriscariam sempre ligar os indivíduos a formas de reconhecimento alienantes. Sobre este último ponto, Honneth poderia sem dúvida responder que as exigências de respeito à liberdade e dignidade, tradicionalmente orientadas ao direito, devem ser consideradas como expectativas de reconhecimento das quais os teóricos da política devem fazer aparecer a objetividade. O debate conduziria sem dúvida então a um consenso em torno da ideia que o reconhecimento nunca pode ser pensado sem luta, que não há sem dúvida nunca reconhecimento totalmente satisfatório, e que o ponto de vista crítico deve ser buscado nas experiências de falta de reconhecimento mais que nas exigências de um reconhecimento satisfatório. Isto faria parecer, por conseguinte, que as divergências

\footnotetext{
${ }^{6}$ P. Molinier, "Le care à lépreuve du travail”, in Raison pratique, 18, op. cit.
} 
analíticas remetem a diferenças de estratégia política ${ }^{7}$. Conquanto Honneth e Dejours considerem ambos a injustiça social e a dominação a sério, eles não consignam da mesma a exigência de autonomia nos seus dispositivos teóricos. Para Honneth, trata-se, sobretudo, da explicitação do ponto de vista pré-teorético da crítica teórica o que constitui a lacuna principal, e as experiências de negação de reconhecimento tem precisamente por interesse identificar as fontes afetivas das dinâmicas práticas e cognitivas de resistência à dominação e à injustiça. Para Dejours, mais do que a metodologia de uma teoria crítica da sociedade, é a técnica psicanalítica que define a maneira pela qual uma teoria pode contribuir com a emancipação, de sorte que são as condições positivas da emancipação e não mais as condições da crítica da dominação e da injustiça que devêm determinantes.

Um debate mais fundamental ainda poderia concernir à maneira pela qual Honneth remete a necessidade de reconhecimento à constituição intersubjetiva da individualidade e à problemática da relação positiva a si. A ideia de relação positiva a si aparecerá sem dúvida obscura e enganosa ao psicanalista. Mas, aqui ainda, convergências poderiam aparecer a partir dos últimos textos8, Honneth antecipa que o reconhecimento intersubjetivo supõe, de uma parte, um tipo de identificação primária a outrem (que é preciso supor para considerar o fato que olhar, o comportamento e o julgamento de outrem me concernem de modo diferente que o comportamento animal, por exemplo) e, de outra parte, um tipo de identificação primária a seus desejos e a seus sentimentos (é preciso que exista para mim para poder relacioná-los a mim mesmo o julgamento que outrem faz acerca de mim). Mesmo se esta identificação primária a si seja descrita por meio de um novo conceito de reconhecimento, Honneth conforma assim um espaço teórico, onde a relação a si se constitui subsumida à relação intersubjetiva, onde, para, além disso, a relação consigo mesmo sob a forma do sofrimento e defesas pode ser levada em conta. Restaria então saber se a questão do reconhecimento deve ser referida de todo à questão da relação positiva a si, isto é, à identidade e, se tal é o caso, como? Dejours admite que a importância de expectativas de reconhecimento deriva notadamente do papel que ele desempenha na constituição da identidade, mas ele assinalaria talvez novamente que o reconhecimento trazendo uma contribuição positiva à identidade relacionada ao "fazer" e não sobre o "ser" do indivíduo. Convém, portanto, desconfiar-se de todas as expectativas (ou efeitos) de reconhecimento relacionadas diretamente à identidade como tal, a objeção poderia ser endereçada a Honneth por associar de modo muito direto reconhecimento e relação positiva a si (sem a tematização explícita da atividade como lugar de realização possível da identidade e como objeto específico de uma forma de reconhecimento particular, aquela relativa ao fazer e não ao ser).

\section{RECONHECIMENTO E SOCIOLOGIA DO TRABALHO}

Sem que se pretenda apresentar uma síntese exaustiva de tudo o que foi dito sobre a relação reconhecimento-trabalho na sociologia alemã contemporânea, concentrar-nos-emos agora sobre as utilizações frankfurtianas do conceito de reconhecimento cuja função é descrever a natureza e os efeitos das transformações

\footnotetext{
${ }^{7}$ Sobre este ponto, A. Honneth, «La dynamique sociale du mépris. D’où parle une théorien critique ?», et «Conscience morale et domination de classe. De quelques difficultés dans l'analyse des potentiels normatifs d'action», in La société du mépris. Vers une nouvellethéorie critique, La Découverte, 2006.

${ }^{8}$ A. Honneth, La Réification. Petit traité de théorie critique, Gallimard, 2007. 
organizacionais ligadas à flexibilização do trabalho e à introdução de novas normas de gerenciamento. Enquanto Honneth se contenta em seus escritos de filosofia social em assinalar que a ideia de reconhecimento diz respeito às expectativas de reconhecimento (reconhecimento de magnitude normativa) e normas sociais de reconhecimento (reconhecimento como fato social), Voswinkel ET Kocyba ${ }^{9}$, pesquisadores do Instituto de Pesquisa Social, tentam descrever a construção social das expectativas de reconhecimento e as transformações das normas sociais de reconhecimento. Seus textos giram em especial em torno de duas questões. Primeiramente, é preciso considerar se o néo-management tira algumas de suas especificidades do fato que ele constitui um gerenciamento do reconhecimento, ou se antes de tudo considerar é ele simplesmente solidário da substituição de um novo modelo de reconhecimento de um modelo anterior? Em segundo lugar, como avaliar os efeitos da instrumentalização do reconhecimento no neomanagement e quais são as consequências que devem ser tiradas quanto ao valor das próprias demandas de reconhecimento. Apresentaremos a seguir a maneira pela qual esses autores formulam estes problemas e vejamos como o próprio Honneth tenta responde-los.

\section{DO FORDISMO AO PÓS-FORDISMO: APRECIAR E ADMIRAR}

O ponto de vista de Voswinkel, defendido em sua tese de habilitação e em diferentes artigos, é que a passagem do fordismo ao pós-fordismo é marcada pela substituição de um modelo de reconhecimento a outro. O fordismo repousa, em parte ao menos, sobre a institucionalização de um modo de reconhecimento diferente daquele do pós-fordismo. Um remete ao reconhecimento como "admiração" (Bewunderung), ao "eu admiro o que você faz ou o que você é", o outro ao reconhecimento como apreciação (Würdigung), ao "eu aprecio o que você faz". A apreciação remete ao fato que certos indivíduos são reconhecedores de outros indivíduos cujos esforços e o engajamento os quais eles evidenciam em suas ações, quaisquer que sejam as capacidades e o sucesso dessas ações; ele é fundamentalmente horizontal no sentido em que depende do pertencimento a comunidades que partilham valores comuns, que permitindo apreciar os esforços de seus membros. Neste sentido, ele é uma modalidade de intercâmbio social, ou um aspecto da constituição dos grupos sociais. A admiração, ao contrário, remete ao prestígio vinculado aos recursos, capacidades e ao sucesso; ele brota de uma relação de reconhecimento que pode chamar-se de "vertical", no sentido onde ele coloca imediatamente o indivíduo cujo valor é reconhecido por sua posição de superioridade em relação a outros indivíduos. A estima é o modo de reconhecimento que convém ao trabalho por prescrição e ao emprego de longa duração do fordismo; ela é relativa aos esforços consentidos para aplicar as prescrições de modo adequado. Ao contrário, a admiração corresponde ao trabalho por projeto e ao emprego de duração determinada. Ele diz respeito mais sobre os recursos diversos que os indivíduos podem mobilizar na condução de projetos, sobre as capacidades as quais os indivíduos evidenciam ao levar esses projetos a bom termo e sobre os sucessos de suas iniciativas10.

\footnotetext{
${ }^{9}$ Veja-se em especial os dois volumes coletivos que eles estimularam e dos quais participaram: U. Holtgrewe, S. Voswinkel, G. Wagner, Anerkennung und Arbeit, Uvk, Konstanz, 2000; A. Honneth, Befreiung der Mündigkeit. Paradoxien des gegenwärtigen Kapitalismus, Campus, Frankfurt, 2002.

${ }^{10}$ Veja-se S. Voswinkel, «Anerkennung der Arbeit im Wandel. Zwischen Würdigung und Bewurderung», in U. Holtgrewe, S. Voswinkel, G. Wagner, Anerkennung und Arbeit, op. cit. ; voir aussi S. Voswinkel, «Bewunderung ohne Würdigung ? Paradoxien der Anerken- nung doppelt subjektivierter Arbeit», in A. Honneth, Befreiung der Mündigkeit. Parado- xien des gegenwärtigen Kapitalismus, op. cit. ; S. Voswinkel, Anerkennung und Reputation. Die Dramaturgie industrieler Beziehungen, Uvk, Kontanz, 2001.
} 
Para apreender os aportes da contribuição de Voswinkel, pode ser útil cotejar este diagnóstico à maneira pela qual Honneth interpreta a passagem do fordismo ao pósfordismo. Para este último, resulta em parte ao menos do desenvolvimento das lutas por reconhecimento, lutas contra o modelo de normas tayloristas do valor do trabalho. $O$ pós-taylorismo resultaria, portanto, em parte ao menos, de um sucesso obtido pelos assalariados na sua luta por serem reconhecidos como algo mais que indivíduos aplicando prescrições, para serem reconhecidos em sua liberdade e criatividade. Isto se caracterizaria por uma individualização dos modos de reconhecimento, uma vez que o trabalho não deve mais ser avaliado por critérios gerais ligados à organização técnica do trabalho, mas sobre a base das contribuições individuais. No esquema honnetiano, o pós-fordismo é solidário de um progresso porquanto se exprimem nele desmandas de reconhecimento que não poderiam se exprimir de tal modo no fordismo, o problema residiria em que se o pós-fordismo libera demandas de reconhecimento, ele se constitui ao mesmo tempo num obstáculo à satisfação delas ${ }^{11}$.

O diagnóstico de Voswinkel toma o contrapé daquele de Honneth. Voswinkel sustenta que não se deveria deixar-se levar pela ilusão que com o declínio do fordismo, são os modelos institucionalizados de reconhecimento que desaparecem para dar lugar a relações de reconhecimento mais maleáveis e mais livres. A situação atual é, ao contrário, caracterizada por um duplo movimento de desinstitucionalização e de reinstitucionalização do reconhecimento. A individualização das demandas de reconhecimento não é, por conseguinte, algo a ser concebido como uma liberação das demandas de reconhecimento, mas como o efeito de um novo tipo de pressão normativa, a qual conduz os indivíduos a tentar fazer valer a qualidade de seu trabalho sob um modo individualizado. Voswinkel assinala, além disso, que se nós estamos antes numa situação de passagem de um modelo de reconhecimento a outro, nas inúmeras situações de trabalho, essas duas normas de reconhecimento se superpõem engendrando conflitos normativos.

Entre Voswinkel, o sociólogo do trabalho, e Honneth, o filósofo no qual ele se inspira, um ponto de desacordo concerne manifestamente na definição da relação entre instituições e demandas por reconhecimento. Para Honneth, as demandas por reconhecimento são concebidas como uma fonte de progresso social e como a alavanca da crítica social. Disso resultam duas consequências. De uma parte, a questão da construção institucional das demandas por reconhecimento não atrai muito sua atenção. De outra parte, a crítica social volta-se mais sobre os processos sociais que interditam a satisfação das demandas por reconhecimento que sobre as situações onde as instituições aprisionam os indivíduos ao dar-lhes satisfação das demandas por reconhecimento que elas mesmas contribuíram para constituir. Para Voswinkel, está claro que a satisfação das demandas por reconhecimento não é sempre positiva, como a instrumentalização do reconhecimento no néomanagement o prova. Esta é uma questão que nos conduz ao problema daquilo que se pode chamar de reconhecimento como dominação e ideologia, problema ao qual Kocyba consagrou várias contribuições.

\section{O PREÇO DO RECONHECIMENTO}

\footnotetext{
${ }^{11}$ A. Honneth, M. Hartmann, «Paradoxes du capitalisme : un programme de recherche» et A. Honneth, «Capitalisme et réalisation de soi : les paradoxes de lindividuation» in La Société du mépris, op. cit.
} 
Kocyba procede a um exame crítico da ideia segundo a qual o pós-fordismo constituiria um progresso em matéria de reconhecimento. Conhece-se a noção [idée voulant] de que o taylorismo seja fundado sobre um desprezo da subjetividade do trabalhador, ela sendo considerada tão somente como um fator de perturbação em relação à organização científica do trabalho. Conhece-se igualmente a noção de que o novo gerenciamento oferece um reconhecimento mais satisfatório ao indivíduo que trabalha, uma vez que ele propõe reconhecer o valor da integralidade de sua pessoa no trabalho: não mais simplesmente do indivíduo como força de trabalho, mais igualmente enquanto criatividade e responsabilidade. Pode-se contestar que se trata aí de verdadeiros progressos. O reconhecimento da subjetividade à qual o novo gerenciamento procede não é sem contrapartida. De uma parte, o assalariado é condenado a uma completa instabilidade, uma vez que passa de um reconhecimento ex ante, definido pelas condições a priori da competência ligada à posse de uma qualificação, a um reconhecimento ex post, que é largamente independente da realidade de seu trabalho, porquanto dependa principalmente da consecução do projeto, isto é, da maneira pela qual é avaliado pela hierarquia e pelo mercado ${ }^{12}$. De outra parte, o trabalho, não sendo mais submetido a prescrições rígidas, identifica sua qualidade ao investimento pessoal do assalariado na consecução do projeto. Ou seja, uma vez que este engajamento não é materializável, é necessário que o assalariado obre ele mesmo para fazer com seja reconhecido: é necessário que ele apresente sua identidade no trabalho, tanto dando testemunho de seu engajamento pessoal no projeto quanto de sua capacidade de mobilizar uma rede de colaboradores competentes e de acompanhar, se não o puder antecipar, todas as modificações organizacionais requeridas. O assalariado é assim submetido a "coações de auto-apresentação" [contraintes de présentation de soi], as quais constituem de fato uma nova forma de negação da subjetividade. $O$ néomanagement pretende que a nova organização do trabalho ofereça possibilidades de realização de si no trabalho, no entanto mais que uma suprassunção da alienação taylorista, é uma nova "fenomenologia da alienação que se desenvolve"13

O problema que é posto por Kocyba é duplo. É, de um lado, que as demandas por reconhecimento são instrumentalizadas pelo gerenciamento, e que a promoção do tema do reconhecimento constitui uma ferramenta destinada a produzir uma organização mais eficaz ainda que aquela do taylorismo, antes de ser uma resposta às reivindicações legítimas do trabalho. E, de outro lado, que os ganhos do reconhecimento permanecem frequentemente obscuros para os próprios agentes (por exemplo, o reconhecimento que eles declaram buscar, aqueles de seus colegas, não é sempre o que eles buscam efetivamente, aquele da hierarquia), e que por meio das relações de reconhecimento passam formas de autocontrole e de relação de poder as quais permanecem por sua vez tão obscurecidas para os agentes que as relações de trabalho são frequentemente o lugar de uma discrepância entre reconhecimento esperado e reconhecimento concedido. Neste contexto, onde as expectativas de reconhecimento são obscuras e endereçadas à hierarquia, em que a instrumentalização do reconhecimento pode aparecer como um dispositivo de legitimação da dominação e da desigualdade, ou como uma ideologia. Isto não conduz Kocyba a criticar a teoria do reconhecimento como tal,

\footnotetext{
${ }^{12}$ H. Kocyba, «Der Preiss der Anerkennung», ibid.

${ }^{13} \mathrm{H}$. Kocyba, «Der Preiss der Anerkennung », ibid. H. Kocyba, « Die falsche Aufhebung der Entfremdung. Über die nomative Subjektivierung der Arbeit im Postfordismus», in M. Hirsch (éd.), Psychoanalyse und Arbeit : Krea- tivität, Leistung, Arbeitstörungen, Vandenhoeck \& Ruprecht, Göttingen, 2000; H. Kocyba, «Selbstverwirklichungszwänge und neue Unterverfungsformen. Paradoxen der Kapilalis- mus Kritik», in Arbeitsgruppe SubArO (éd.), Ökonomie der Subjektivität - Subjektivität der Ökonomie, Édition Sigma, Berlin, 2005.
} 
mas antes a tentar denunciar essas formas de reconhecimento falseadas à luz da exigência de um reconhecimento verdadeiro ${ }^{14}$.

O próprio Honneth tentou considerar este tipo de problema distinguindo formas de reconhecimento ideológicas e formas de reconhecimento não ideológicas. Há ideologia do reconhecimento quando uma instituição emite promessas de reconhecimento que ela não pode satisfazer, e é este tipo de ideologia do reconhecimento que poderia ser observada na organização atual do trabalho ${ }^{15}$. O problema não estaria, portanto, na natureza das demandas por reconhecimento que provém dos indivíduos, mas no fato que estas não são satisfeitas. O neomanagement seria solidário de um progresso frente ao taylorismo, uma vez que formula promessas de reconhecimento mais satisfatórias que aquelas do taylorismo, e o desafio hoje lançado à crítica social seria o de contribuir para certificar-se de que a organização do trabalho e da sociedade permita satisfazê-las. Pode-se, entretanto, objetar se o problema assinalado pelo conceito de ideologia pode ser reduzido àquele de promessas não realizáveis. Classicamente, este conceito designa igualmente a legitimação das dominações e desigualdades. Ou seja, os problemas sublinhados por Kocyba conduzem à ideia de que as normas de reconhecimento têm uma função ideológica neste sentido16, elas fazem aparecer por isso mesmo o que há de problemático em conceber a passagem do fordismo ao pósfordismo como um progresso.

A sociologia do trabalho inspirada por Honneth se apresenta, por conseguinte, como um espaço de debate mais que como uma escola homogênea. É, portanto, temerário esboçar uma confrontação com a Psicodinâmica do Trabalho a qual, igualmente, poderia ser mobilizada em benefício de diagnósticos sociopolíticos divergentes. Entre as duas perspectivas, um ponto de desacordo diria respeito sem dúvida o ponto de vista a partir do qual os diagnósticos são estabelecidos. Partindo do par conceitual expectativa de reconhecimento e fato social do reconhecimento, os approaches Frankfurt anos tendem a privilegiar a maneira pela qual as normas de reconhecimento estruturam os discursos gerenciais e os efeitos de subjetivação que eles induzem. Do ponto de vista da Psicodinâmica do Trabalho, é a própria atividade de trabalho que constitui o objeto de análise, de sorte que a questão das técnicas de organização do trabalho é colocada em primeiro plano, enquanto a questão do discurso gerencial aparece como secundária, senão como mistificadora. A avaliação individualizada das performances e a démarche da qualidade total constituem o coração do problema, a segunda implicando um desconhecimento tendencial da realidade e da utilidade do trabalho, enquanto a primeira oferece tão somente reconhecimento do trabalho pelos pares. Os discursos gerenciais certamente não podem ser postos como simples discursos de legitimação exteriores às atividades, na medida em que os indivíduos devem sempre se referir a eles para descrever seu trabalho, mas a psicodinâmica do trabalho assinala que a experiência do trabalho coloca os indivíduos em posição crítica frente às práticas discursivas gerenciais funcionando como prescrição e promessa.

\footnotetext{
${ }^{14}$ H. Kocyba, «Die falsche Aufhebung der Entfremdung. Über die normative Subjektivie- rung der Arbeit im Postfordismus», in M. Hirsch (éd.), Psychoanalyse und Arbeit: Krea- tivität, Leistung, Arbeitstörungen, Vandenhoeck \& Ruprecht, Göttingen, 2000; H. Kocyba, «Selbstverwirklichungszwänge und neue Unterverfungstomen. Paradoxen der Kapilalis- mus Kritik», in Arbeitsgruppe SubArO (éd.), Ökonomie der Subjektivität-Subjektivität der Ökonomie, Édition Sigma, Berlin, 2005.

${ }^{15} \mathrm{~A}$. Honneth, «La reconnaissance comme idéologie», in La Société du mépris, op. cit.

${ }^{16}$ Poder-se-ia desenvolver esta discussão interrogando-se sobre a função do dispositivo Vae no pós-fordismo, a este respeito, veja-se D. Laoppe, «Formes et vécus du déni de reconnaissance : retour sur l'échec en validation des acquis de l'expérience», et $E$. Renault, «Reconnaissance ou validation? La reconnaissance entre critique et idéologie», in F. Neyrat (dir.), La Validation des acquis de l'expérience, Éditions du Croquant, Broissieux, 2007.
} 
Uma questão posta explicitamente por Marie Grenier-Pezé no documentário "Ele não morreram todos, mas estão todos feridos" (2006) é de saber se o desejo de reconhecimento não conta entre os fatores explicando a adesão a estas técnicas organizacionais. Prosseguindo esta interrogação, seríamos sem dúvida reconduzidos a formular a problemática do reconhecimento como ideologia antecipando que a contribuição das expectativas de reconhecimento à ideologia passa pela ausência de solução de continuidade entre reconhecimento da atividade ("do fazer") e o reconhecimento da identidade ("do ser"). Como se sabe o que está em jogo no trabalho, não é somente a utilidade para a empresa, mas também a competência a e a utilidade social, estes últimos elementos definem a identidade profissional ou de ofício. A identidade pessoal entra diretamente em jogo por intermédio daquela identidade profissional. Talvez fosse, ademais, fecundo buscar determinar qual pode ser a contribuição das expectativas de reconhecimento ancoradas na identidade coletiva atinentes à constituição das ideologias defensivas as quais, em certas condições, emergem da atividade de trabalho como tal. Sobre a questão da ideologia também, uma confrontação das problemáticas pós-marxistas de Frankfurt com aquelas da psicodinâmica do trabalho poderia revelar-se fecunda.

Data da submissão: 11/07/2019

Data da aprovação: 16/07/2019 